\title{
Ammonium Polyphosphate Intercalated Yttrium-Doped Layered Double Hydroxides to Enhance the Thermal Stability and Flame Retardancy of Poly(Lactic Acid)
}

\author{
Yufei Dai $\mathbb{D}^{1,2}$ Hongzhang Cao $\mathbb{D}^{1},{ }^{1}$ Xiaoli Yu, ${ }^{1}$ Dequan Han, ${ }^{1}$ Huhu Tian, ${ }^{1}$ Liying Guo, ${ }^{1}$ \\ and Xiaodong Zhou ${ }^{1}$ \\ ${ }^{1}$ State Key Laboratory of Baiyunobo Rare Earth Resource Researches and Comprehensive Utilization, Baotou Research Institute of \\ Rare Earths, Baotou 014030, China \\ ${ }^{2}$ Inner Mongolia University, College of Chemistry and Chemical Engineering, Hohhot 010021, China
}

Correspondence should be addressed to Hongzhang Cao; btxtychz@163.com

Received 7 December 2021; Accepted 27 January 2022; Published 27 February 2022

Academic Editor: Alain Durand

Copyright (c) 2022 Yufei Dai et al. This is an open access article distributed under the Creative Commons Attribution License, which permits unrestricted use, distribution, and reproduction in any medium, provided the original work is properly cited.

\begin{abstract}
The flammability of the biodegradable plastic PLA limits its application in industrial fields with high flame-retardant requirements. This paper provides a novel strategy for constructing refractory and thermostable PLA composites using layered double hydroxides (LDHs) chemically modified with ammonium polyphosphate (APP). XRD, FT-IR, SEM-EDS, and TEM confirm that the goal of LDHs has been successfully prepared. The thermal stability and combustion behavior of PLA composites were evaluated by the thermogravimetric analysis (TGA) and cone calorimetry tests (CCT). The crystallization behavior and tensile performances were also examined. The results showed that the incorporation of $15 \mathrm{wt} \%$ MgAlY-APP-LDHs practically makes the PLA composites reach the UL-94 V-0 grade. There were $43 \%$ and $20 \%$ reduction in the PHRR and THR of PLA/15APP-LDHs respectively due to the catalytic effect of Y elements and barrier effects of LDHs, which was a major performance against fire hazards. Furthermore, the increase in crystallinity and the decrease in mechanical strength of PLA composites are attributed to the nucleation of LDHs. In short, this research introduces the production of multifunctional PLA composites through APP intercalation of LDHs, which are deemed as prospective candidates for the next generation of sustainable plastics products.
\end{abstract}

\section{Introduction}

The global plastics market is expected to grow at a rate of $5 \%$ per year. The excessive use of petroleum-based plastics has caused the problem of "white pollution" and has seriously threatened the Earth's ecological environment. To meet the growing demand for plastics, the effective strategy involved the production of biodegradable plastics. PLA is a biodegradable polymer with favorable biocompatibility, which can be obtained from renewable resources. Therefore, PLA is considered a potential substitute for petroleum-based plastics [1-3]. In addition, as one of the most promising "green plastics," PLA is widely used in packaging, agricultural, biomedicine, and other fields on account of its excellent mechanical properties, high pellucidity, easy processing, etc. [4-6], while the poor flame retardancy of PLA seriously restrains its applications in emerging fields such as electronic devices, automobiles, and building materials $[7,8]$. To circumvent this problem, adding flame retardants to PLA is an effective strategy to combat fire risk [9-11].

To date, halogen-based flame retardants show a negative impact on the environment due to their toxic combustion products, and these side effects have limited its application [12].Phosphorus-containing compounds are efficient flame retardants for polymers. However, it is expected to cause a 
decrease in mechanical properties [13]. Metal-hydroxides are flame retardants used in various merchant products. The endothermic decomposition of metal-hydroxides can decrease the combustion performance of flammable materials and release water into the vapor phase to dilute the blaze [14]. Their main disadvantages are low flameretardant efficiency and poor compatibility with common polymers. Thus, excessive addition will lead to the deterioration of the mechanical characters of the material.

With the development of nanotechnology, huge opportunities are provided for flame-retardant materials [15-17]. Compared with traditional flame retardants, the impressive effect of nanosized additives is to significantly inhibit the HRR of the polymer. As a consequence, more attention has concentrated on finding effective nanofillers to improve different properties of the polymer. The most widely used nanomaterials are carbon nanotubes [18], graphene [19, 20], nanooxides [21], and nanoclays [22]. They change the degradation pathway of the polymer and form a highperformance char layer, which will restrict the passage of heat through the underlying material [23-25]. Other nanoparticles that show a unique effect on polymers are LDHs. LDHs is considered an emerging layered inorganic nanofiller, LDHs may raise the flame retardancy of polymer material owing to their flexible chemical components and distinct structure.

LDHs are anion-exchangeable layered compounds, and the interlayer area contains charge-compensating anions and solvent molecules. LDHs can be defined as $\left[\mathrm{M} 2+1-\mathrm{XM} 3+x(\mathrm{OH})_{2}\right]^{x+}\left[\left(\mathrm{A}^{n-}\right)_{x / \mathrm{n}} \cdot \mathrm{mH}_{2} \mathrm{O}\right]^{x-}$, where $\mathrm{M}^{2+}$ and $\mathrm{M}^{3+}$ are metal cations, such as $\mathrm{Mg}^{2+}, \mathrm{Zn}^{2+}, \mathrm{Al}^{3+}$, and $\mathrm{Fe}^{3+}$, which are in balance with the interlayer anions $\left(\mathrm{An}^{-}\right)$, such as $\mathrm{NO}_{3}{ }^{-}, \mathrm{OH}^{-}$, and $\mathrm{CO}_{3}{ }^{2-}$. $\mathrm{LDHs}$ have a wide range of applications in drug release [26], adsorbents [27, 28], catalysis $[29,30]$, supercapacitors [31], and flame retardants [32-34]. As a nanoflame retardant, LDHs have been widely used in plenty of polymers including EVA, PP, and EP [35-37]. Similar to other common inorganic flame retardants, when LDHs are added alone, their fire resistance is very low. Therefore, it is necessary to modify the LDHs so that the flame-retardant properties of the composite materials are improved [38]. For example, Shan et al. [39] synthesized $\mathrm{NiFe}, \mathrm{NiAl}$, and $\mathrm{NiCr}$ LDH-SDS by the coprecipitation method (SDS stands for sodium dodecyl sulfate), together with hexaphenoxycyclotriphosphazene (HPCP) to prepare PLA composites. Thermal and residue analysis showed that all LDHs can improve the fire retardancy of composites.

APP is well known for its nontoxic, environmental protection, and high-performance [40,41]. Although APP has good expansion properties, their flame-retardant effect is not ideal. The thick layer of APP formed during combustion is easily separated from the polymer matrix, so we need to find new ways to balance the flame retardancy and other properties. In previous research, APP and LDHs were simply mixed together physically. Several studies have confirmed that APP intercalating LDHs can further enhance the fire retardancy of resins. For instance, Gao et al. [42] used a solvent mixing method to intercalate APP into LDHs, and compounded with zinc borate (ZB) to prepare PP/APPLDHs/ZB composites. The results showed that the PHRR of the PP containing $20 \mathrm{wt} \%$ APP-LDHs and $2 \mathrm{wt} \% \mathrm{ZB}$ was significantly reduced by $58 \%$. Liu et al. [43]. embedded APP and dye Acid Red 88 (AR88) together in the LDH interlayer. When the LDHs loading was $25 \mathrm{wt} \%$, the composites' PHRR was remarkably reduced by $63 \%$. In view of this, a new strategy for APP intercalation containing rare earth LDHs is proposed, as shown in Figure 1. Subsequently, LDHs were introduced into the PLA to improve its fire retardancy.

\section{Experimental}

2.1. Materials. Sodium hydroxide (99\%) was obtained from Tianjin Yong sheng Fine Chemical Company, Tianjin, China. Ammonium polyphosphate (99\%), magnesium chloride anhydrous (99\%), aluminum chloride (99\%), and yttrium chloride hexahydrate were purchased from Shanghai Energy Chemical, Shanghai, China. PLA (3052D) was supplied by Nature Works, Blair, America. In this experiment, the chemicals were analytically pure without purification.

2.2. Synthesis of the MgAlY-APP-LDHs. The MgAlY-APPLDHs were synthesized via the traditional hydrothermal approach. For MgAlY-APP-LDHs (Mg: Al : Y = $20: 9: 1$ ), the preparation steps were as follows: Firstly, disperse APP $(50 \mathrm{~g})$ in $100 \mathrm{~mL}$ deionized water to make suspension A. Solution B was prepared by dissolving $\mathrm{MgCl}_{2}(20 \mathrm{mM}), \mathrm{AlCl}_{3}$ $(9 \mathrm{mM})$ and $\mathrm{YCl}_{3} \cdot 6 \mathrm{H}_{2} \mathrm{O}(1 \mathrm{mM})$ in $100 \mathrm{~mL}$ deionized water. Subsequently, solution B was added dropwise in suspension A under continuous stirring, and the $\mathrm{pH}$ value of the mixture was controlled at around 10 by $\mathrm{NaOH}(4 \mathrm{M})$. The mixed solution was transferred to an autoclave and hydrothermally reacted at $100^{\circ} \mathrm{C}$ for 24 hours. Afterward, the product was washed alternately in ethanol and deionized water to a $\mathrm{pH}$ of 7 and finally dried in a vacuum box at $80^{\circ} \mathrm{C}$ for 12 hours to obtain the MgAlY-APP-LDHs.

2.3. Preparation of PLA/MgAlY-APP-LDH composites. Both PLA and MgAlY-APP-LDHs were vacuum dried at $70^{\circ} \mathrm{C}$ for $12 \mathrm{~h}$; this step is critical because PLA moisture level affects its properties and can cause its degradation during compounding. The melt blending process used a twinscrew extruder; the rotor operates at a rate of $40 \mathrm{rpm}$ to achieve a stable PLA melt flow. The concentration of MgAlY-APP-LDHs in the PLA composites was specified as $0,5,10,15,20$, or $25 \mathrm{wt} \%$. For the sake of simplicity, PLA/ 5APP-LDHs represent the PLA composites containing 5 wt $\%$ MgAlY-APP-LDHs.

\subsection{Experimental Equipment}

2.4.1. X-Ray Diffraction (XRD). XRD analysis was performed in the Smartlab-3KW (Japan) system with CuKa radiation $(\lambda=1.54184 \AA)$. The scan range of the sample was $5-90^{\circ}$ with $5^{\circ} / \mathrm{min}$. 

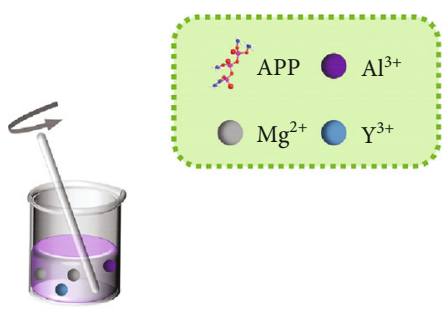

Solution B
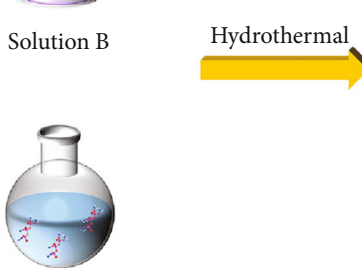

Solution A
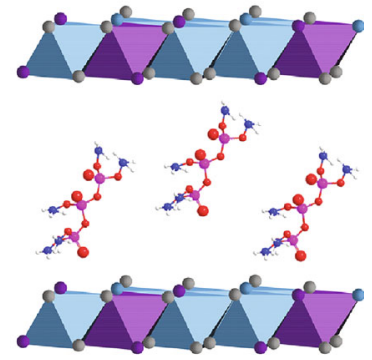

MgAIY-APP-LDH

Figure 1: Synthesis schematic of MgAlY-APP-LDHs.

2.4.2. Fourier Transform Infrared Spectroscopy (FTIR). FTIR (Nicolet NEXUS 670) was used to characterize the functional groups of the samples in the $4000-600 \mathrm{~cm}^{-1}$ spectral range.

2.4.3. Scanning Electron Microscopy-Energy Dispersive Spectrometer (SEM-EDS). The structure and morphology of the LDHs were investigated by SEM (ZEISS Sigma-500, Germany), and the composition was determined through EDS.

2.4.4. Transmission Electron Microscope (TEM). The morphology and size of the LDHs were analyzed by TEM (Thermo Talos F200i, USA).

2.4.5. Thermogravimetric Analysis (TGA). TGA was performed on a TG/DTA 6300 (Hitachi, Japan) thermogravimetric analyzer from $20^{\circ} \mathrm{C}$ to $600^{\circ} \mathrm{C}$ with $10^{\circ} \mathrm{C} / \mathrm{min}$ under $\mathrm{N}_{2}$.

2.4.6. Flame-Retardant Performance Test. The combustion performance of the PLA composites passed the following tests. The UL-94 vertical burning test is measured on the SC-94B instrument (Gottwell, China) according to the ASTM D3801-1996 standard. The sample size is $130 \times 13$ $\times 3 \mathrm{~mm}^{3}$. The CCT of PLA composites were conducted using an FTT cone calorimeter device (UK) on the basis of ISO 5660 at a heat flux of $35 \mathrm{~kW} / \mathrm{m}^{2}$.

2.4.7. Differential Scanning Calorimetry (DSC). The crystallization behavior of PLA composites was examined by DSC (DSC 214, Netzsch, Germany). 5-10 mg of the sample was heated to $200^{\circ} \mathrm{C}$ at a rate of $10^{\circ} \mathrm{C} / \mathrm{min}$ in an argon atmosphere, and it was maintained for 6 minutes to remove the heat history. Then the sample was cooled to $20^{\circ} \mathrm{C}$ and heated to $200^{\circ} \mathrm{C}$ with the same rate. $\chi_{c}$ was calculated by the following equation:

$$
\chi c=\frac{\Delta H_{m}}{\varphi \times \Delta H_{m}^{0}} \times 100 \%,
$$

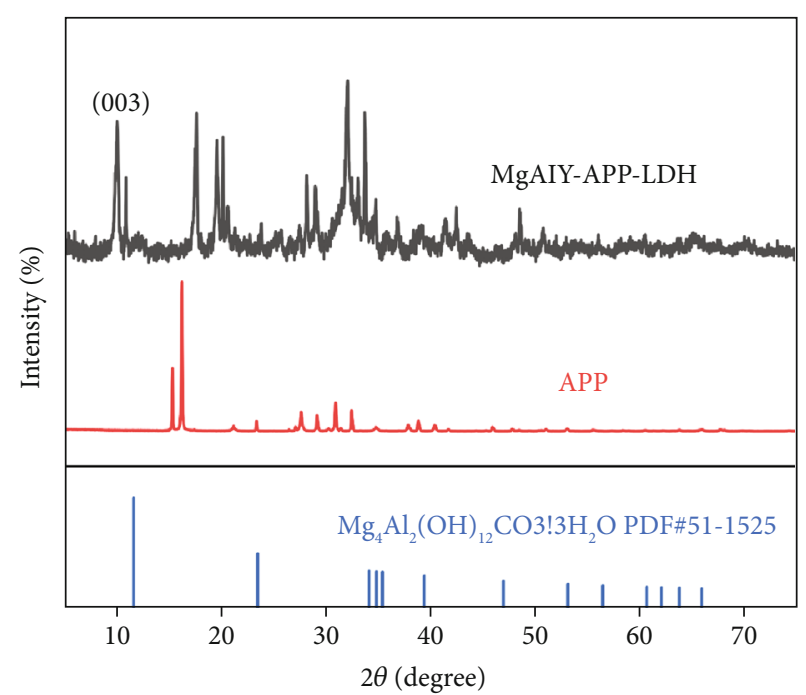

FIgURE 2: XRD patterns of APP and MgAlY-APP-LDHs.

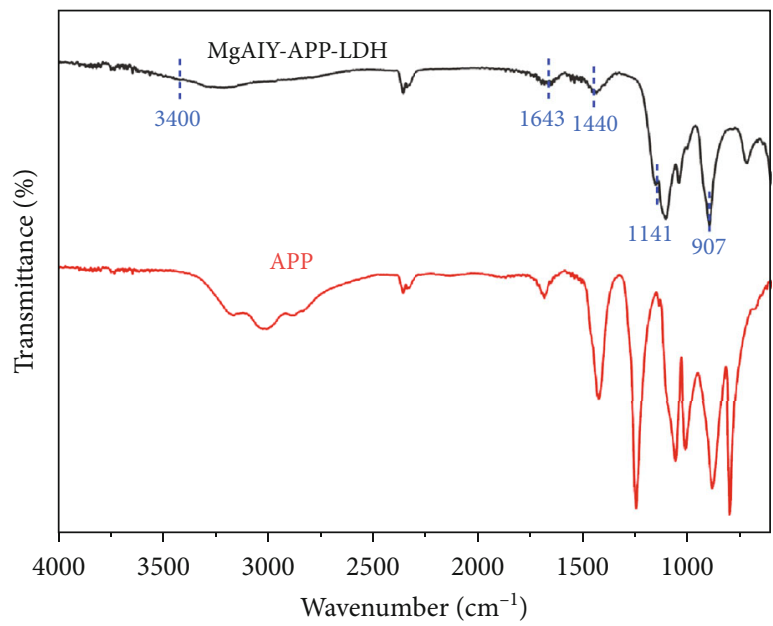

FIGURE 3: FT-IR spectrum of APP and MgAlY-APP-LDHs.

where $\Delta H_{m}^{0}$ was the enthalpy melting of pristine PLA with a value of $93 \mathrm{~J} / \mathrm{g}$ and $\varphi$ was the quality score of PLA [44].

2.4.8. Mechanical Properties. Tensile mechanical testing was conducted using the CTM 6103 testing machine (MTS, China) in the light of GB/T 1040.1-2006 to measure the tensile properties of the composites. The specimen dimensions were $75 \times 5 \times 2 \mathrm{~mm}^{3}$, all tensile tests were carried out with $1 \mathrm{~mm} / \mathrm{min}$.

\section{Results and Discussion}

3.1. XRD of LDHs. Figure 2 shows the XRD patterns of pure APP and MgAlY-APP-LDHs. An obvious (003) characteristic diffraction peak at $2 \theta=9.68^{\circ}$ was observed in the singleintercalation APP-LDH pattern; the result indicated that a typical layered structure is formed. According to the formula $2 d \sin \theta=n \lambda \quad(\lambda=0.154056 \mathrm{~nm}, \quad n=1)$, the resultant 


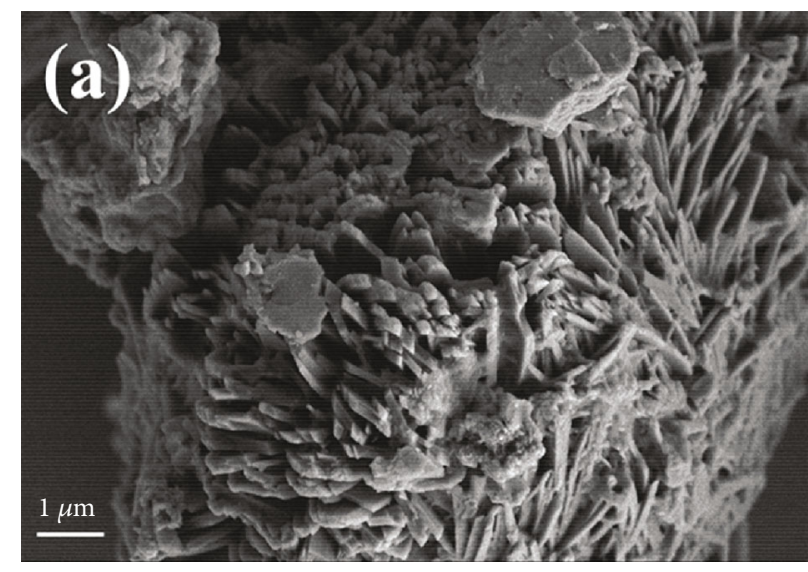

(a)
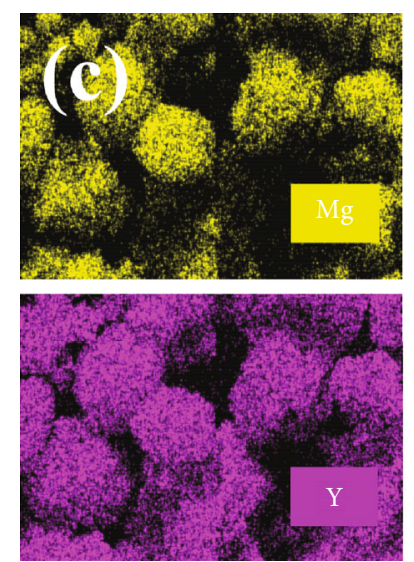

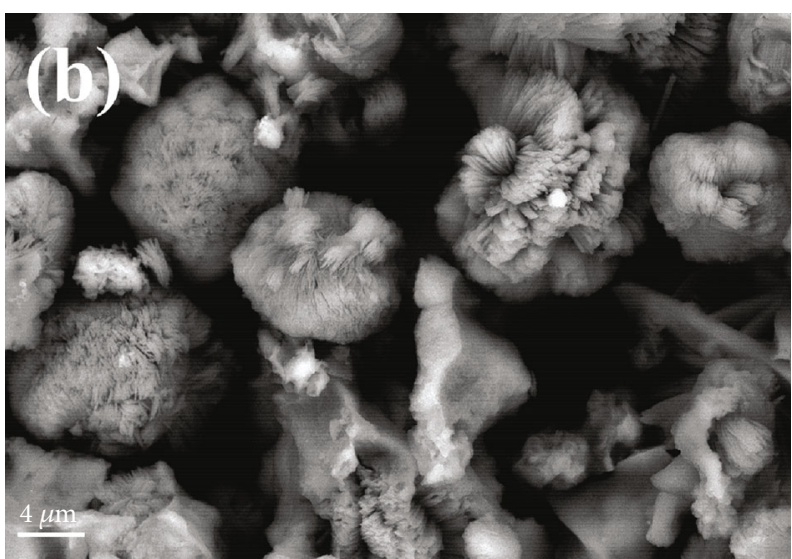

(b)
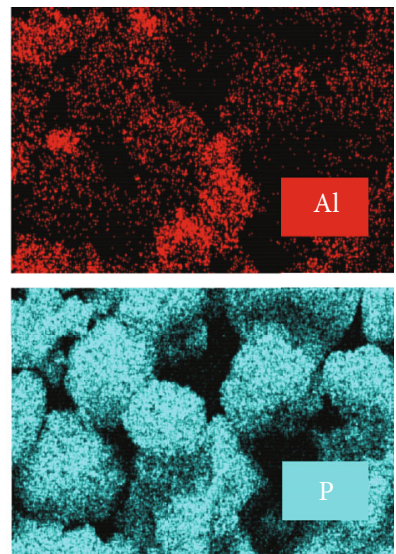

(c)

FIgURE 4: SEM of (a) MgAlY-APP-LDHs and (b, c) the corresponding EDS mapping patterns for the MgAlY-APP-LDHs.

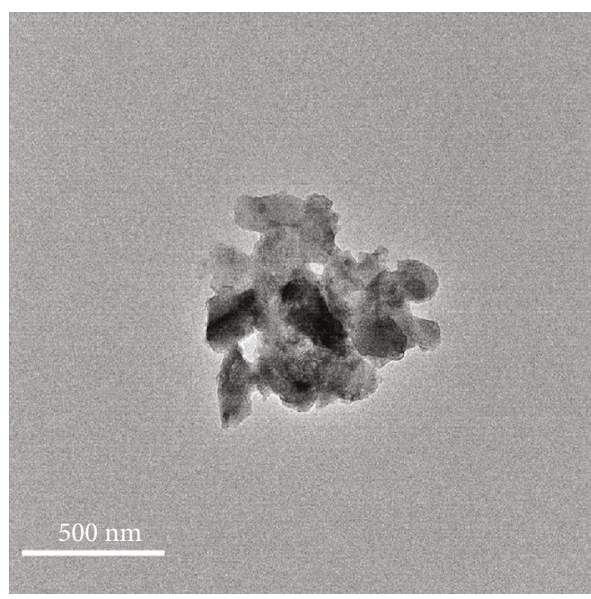

(a)

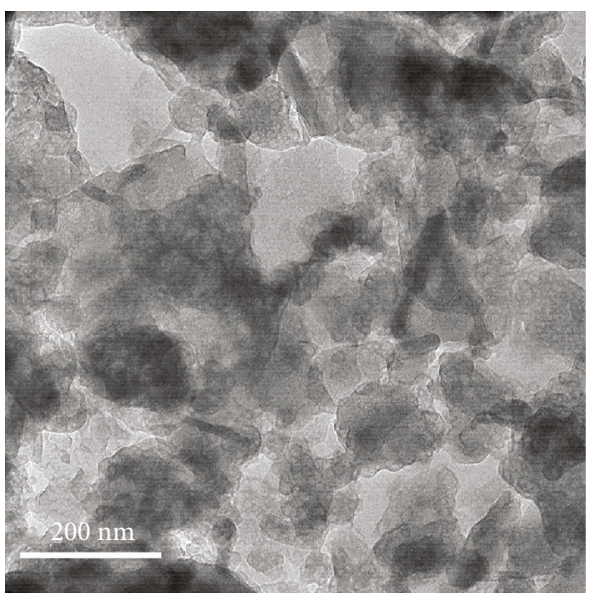

(b)

Figure 5: (a) TEM and (b) magnified TEM images of MgAlY-APP-LDHs. 
calculated interlayer spacing increased from $0.75 \mathrm{~nm}$ of $\mathrm{MgAl}-\mathrm{LDHs}$ to $0.91 \mathrm{~nm}$; it was attributed to the relatively large APP molecules embedded in the LDH interlayer. Nevertheless, MgAlY-APP-LDHs contained a small number of low-intensity Bragg peaks. This may be because LDHs have become more amorphous, so the coherence along the platelet accumulation axis ( $c$-axis) to notice any highintensity (001) Bragg reflection [45]. By comparing the XRD patterns of APP and LDHs, it can be found that no characteristic peaks of APP were observed in LDHs, which also confirms that APP molecules were successfully inserted into the interlayer of LDHs. In other words, APP is not simply physically mixed with LDHs.

3.2. FT-IR of LDHs. This part discusses the FTIR characterization of products (Figure 3). The wide absorption band observed around $3400 \mathrm{~cm}^{-1}-3500 \mathrm{~cm}^{-1}$ corresponds to the stretching vibration of the $\mathrm{O}-\mathrm{H}$ group by water molecules, thus confirming the presence of the hydroxyl groups on LDHs. The peak associated with $\mathrm{H}-\mathrm{OH}$ bending appears at $1643 \mathrm{~cm}^{-1}$, which is also due to the interlayer of $\mathrm{H}_{2} \mathrm{O}$. Furthermore, the bands appear at 1141,907 , and $1440 \mathrm{~cm}^{-1}$ due to the vibration of the $\mathrm{P}-\mathrm{O}$ and $\mathrm{N}-\mathrm{H}$ groups, respectively, indicating the existence of phosphate in the LDHs. The characteristic peaks of LDHs are well displayed, and all the spectroscopic results confirmed that APP molecules are not decomposed and successfully entered the interlayer of LDHs.

3.3. SEM and EDS of LDHs. Figure 4(a) displays the surface morphologies of the LDHs. The LDHs are plate-like nanoparticles with a dimension of $100-300 \mathrm{~nm}$; the relatively small LDHs nanoparticles facilitate their sufficient dispersion in the polymers and raise compatibility with polymers. Beyond this, the embedding of APP will not change the shape and structure of LDHs, which further proves that the target LDHs has been prepared successfully. This agreed with the outcomes from previous studies [46]. Figures 3(b) and 3(c) present the SEM-EDS images of LDHs; the phosphorus is detected by EDS. These results demonstrate the successful modification of LDHs by APP. The EDS mapping confirms that the APP exists in the mezzanine of LDHs. These results are very consistent with the results of the previous XRD and FT-IR analysis.

3.4. TEM of LDHs. Figures 4(a) and 4(b) illustrate the TEM pictures of LDHs. It exhibits the flake-shaped morphology with a diameter of 100-300 nm. Furthermore, LDHs have uniform and nanoscale crystal sizes. It is seen that most of the nanoplates display a hexagonal shape. However, the Van der Waals forces between laminates attract the particles and cause agglomeration.

3.5. TG and DTG of LDHs and Composites. The effect of LDHs on the thermal stability of PLA was obtained by performing TGA on all samples. Figures 5(a) and 5(b) show that pure APP begins to decompose at around $300^{\circ} \mathrm{C}$, and two obvious weight-loss peaks can be observed at $327^{\circ} \mathrm{C}$ and $583^{\circ} \mathrm{C}$. LDHs decompose at a lower temperature than APP; the interlayer moisture will be lost when the tempera-
TAble 1: TGA data of PLA and PLA composites.

\begin{tabular}{lccc}
\hline Sample ID & $\begin{array}{c}T_{i} \\
\left({ }^{\circ} \mathrm{C}\right)\end{array}$ & $\begin{array}{c}T_{\max } \\
\left({ }^{\circ} \mathrm{C}\right)\end{array}$ & $\begin{array}{c}\text { Char residues } \\
(\text { wt } \%)\end{array}$ \\
\hline PLA & 327.20 & 362.76 & 0.02 \\
PLA/5APP-LDHs & 334.53 & 366.48 & 4.77 \\
PLA/10APP-LDHs & 332.54 & 366.98 & 7.72 \\
PLA/15APP-LDHs & 318.44 & 367.31 & 16.48 \\
PLA/20APP-LDHs & 325.60 & 367.66 & 16.00 \\
PLA/25APP-LDHs & 309.44 & 368.09 & 22.98 \\
\hline
\end{tabular}

$T_{i}$ was the temperature at $5 \%$ weight loss.

TABLE 2: UL-94 results of PLA and PLA composites.

\begin{tabular}{lccc}
\hline Samples & $t_{1} / t_{2}(\mathrm{~s})$ & $\mathrm{UL}-94$ & Dripping $(\mathrm{Y} / \mathrm{N})$ \\
\hline PLA & $11.3 / 13.6$ & $\mathrm{NR}$ & $\mathrm{Y}$ \\
PLA/5APP-LDHs & $11.6 / 15.4$ & $\mathrm{~V}-2$ & $\mathrm{Y}$ \\
PLA/10APP-LDHs & $10.6 / 4.5$ & $\mathrm{~V}-2$ & $\mathrm{Y}$ \\
PLA/15APP-LDHs & $1.8 / 3.7$ & $\mathrm{~V}-0$ & $\mathrm{Y}$ \\
PLA/20APP-LDHs & $5.0 / 3.0$ & $\mathrm{~V}-2$ & $\mathrm{Y}$ \\
PLA/25APP-LDHs & $7.9 / 2.2$ & $\mathrm{~V}-2$ & $\mathrm{Y}$ \\
\hline
\end{tabular}

ture is close to $200^{\circ} \mathrm{C}$. The temperature continues to rise to about $200 \sim 450^{\circ} \mathrm{C}$; it will remove the hydroxyl $(-\mathrm{OH})$ on the laminate, and its layered structure will be destroyed simultaneously. When the temperature continues to rise to about $200 \sim 450^{\circ} \mathrm{C}$, the hydroxyl $(-\mathrm{OH})$ on the laminate will be removed, and the layered structure will be destroyed simultaneously. When the temperature is greater than $450^{\circ} \mathrm{C}$, LDHs are completely decomposed into metal oxides and absorb a lot of heat, which reduces the surface temperature of the polymer. Furthermore, the metal oxides will adsorb toxic gases due to their high surface area and large porosity. Meanwhile, the expanded char layer formed by the reaction of metal oxides and polymer degradation products can block the intrusion of heat and achieve the efficient flame retardant.

Table 1 lists the $T_{i}, T_{\max }$, and the char residual percentage of PLA and its composites to comprehensively evaluate their relative thermal stability. Compared with PLA, the $T_{i}$ of PLA/5APP-LDHs composites has increased by $7^{\circ} \mathrm{C}$, while the $T_{i}$ of the composites loaded with $25 \mathrm{wt} \%$ APP-LDHs has been greatly reduced. The reason for this phenomenon may be that as the loading of LDHs increases, it will promote and catalyze the degradation of PLA in the initial stage. Besides, the char layer formed by LDHs slows down the heat release rate of PLA, thereby protecting the PLA matrix from flame degradation. As for $T_{\max }$, all PLA/APP-LDH composites increased; the introduction of $25 \mathrm{wt} \% \mathrm{LDHs}$ increases the $T_{\max }$ from $362.76^{\circ} \mathrm{C}$ to $368.0^{\circ} \mathrm{C}$. However, $T_{\text {HRI }}$ will decrease at high filling volume, so it is a challenge to make the polymer achieve high-efficiency flame retardancy with a low addition of LDHs. Additionally, PLA displayed one-step degradation within $307^{\circ} \mathrm{C} 3377^{\circ} \mathrm{C}$, and the maximum 


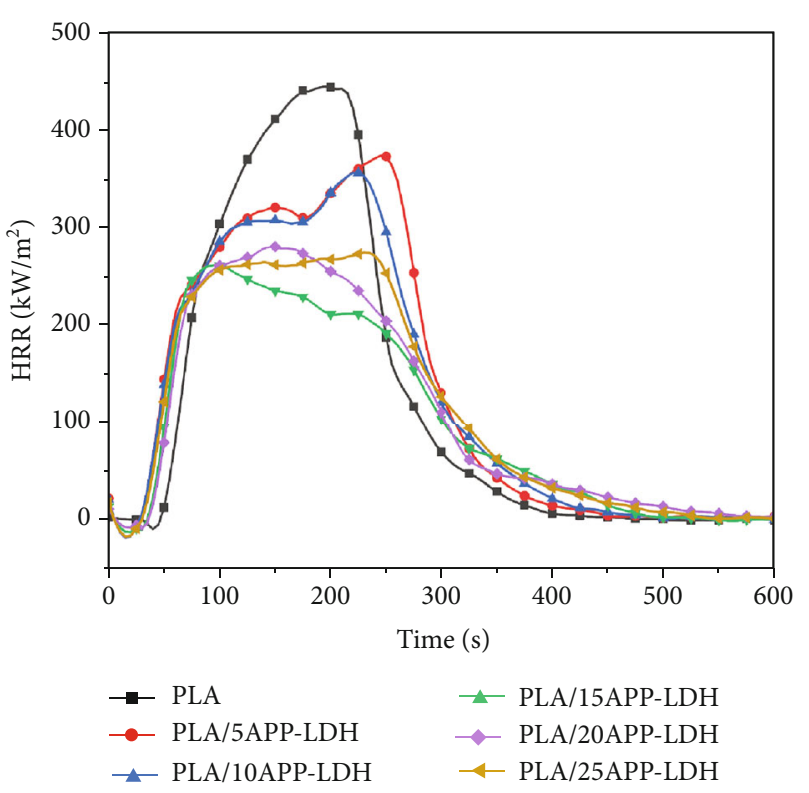

(a)

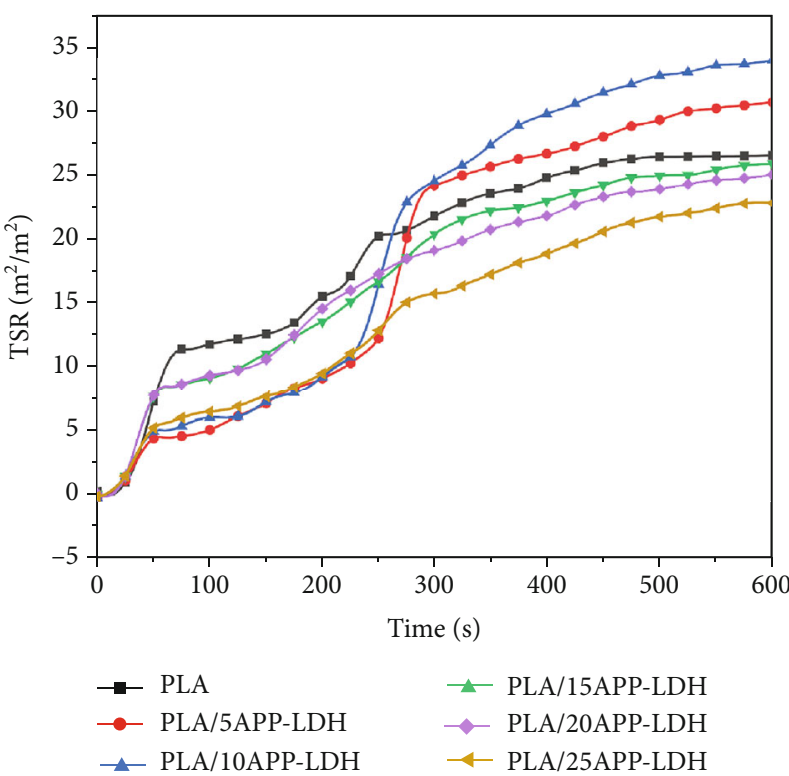

(c)

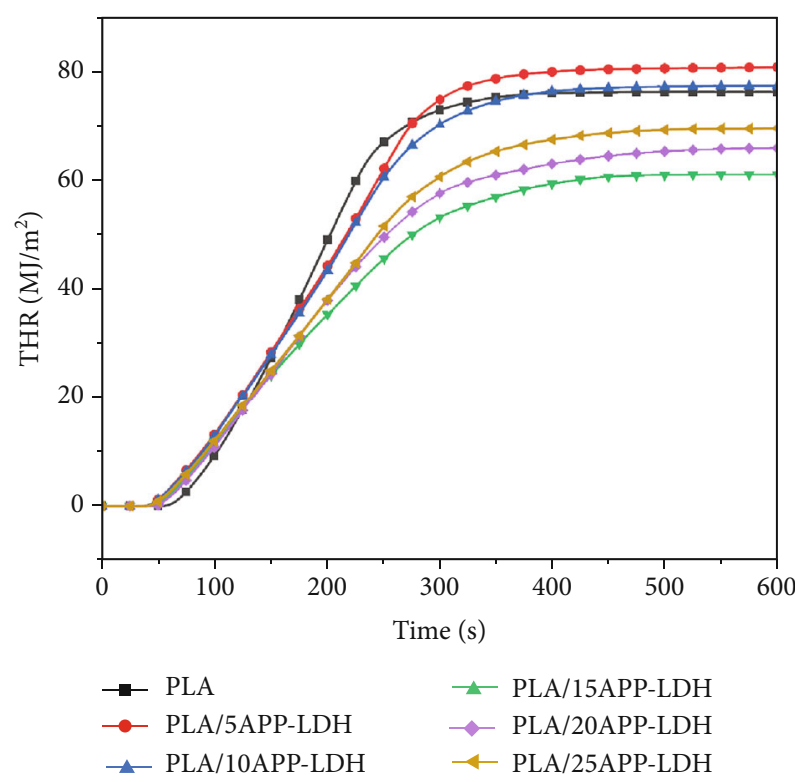

(b)

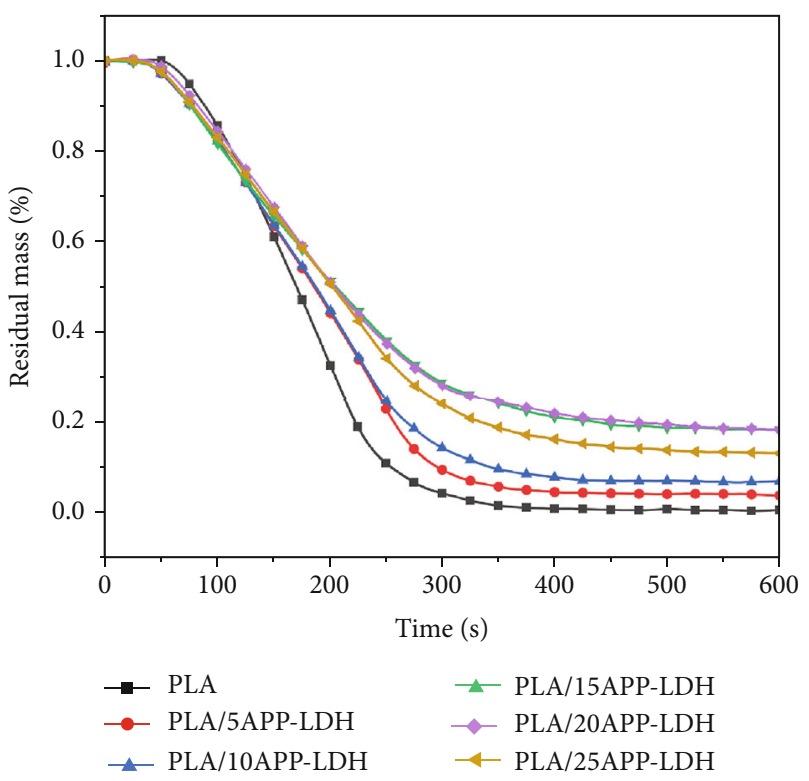

(d)

FIgURe 6: (a) HRR, (b) THR, (c) TSP, and (d) residual mass of PLA composites along with burning time.

TABLe 3: CC data of PLA and its composites.

\begin{tabular}{|c|c|c|c|c|c|c|c|}
\hline Samples & $\begin{array}{l}\text { TTI } \\
(\mathrm{s})\end{array}$ & $\begin{array}{c}\text { PHRR } \\
\left(\mathrm{kW} / \mathrm{m}^{2}\right)\end{array}$ & $\begin{array}{c}T_{\mathrm{PHRR}} \\
(\mathrm{s})\end{array}$ & $\begin{array}{c}\text { THR } \\
\left(\mathrm{MJ} / \mathrm{m}^{2}\right)\end{array}$ & $\begin{array}{c}\text { EHC } \\
(\mathrm{MJ} / \mathrm{kg})\end{array}$ & $\begin{array}{c}\text { TSR } \\
\left(\mathrm{m}^{2} / \mathrm{m}^{2}\right)\end{array}$ & FRI \\
\hline PLA & 55 & 457 & 205 & 76 & 39 & 30 & 1.00 \\
\hline PLA/5APP-LDHs & 40 & 376 & 230 & 80 & 18 & 34 & 0.84 \\
\hline PLA/10APP-LDHs & 40 & 357 & 220 & 77 & 47 & 38 & 0.92 \\
\hline PLA/15APP-LDHs & 41 & 261 & 100 & 61 & 61 & 29 & 1.63 \\
\hline PLA/20APP-LDHs & 40 & 287 & 155 & 65 & 78 & 28 & 1.35 \\
\hline PLA/25APP-LDHs & 41 & 276 & 235 & 69 & 52 & 25 & 1.36 \\
\hline
\end{tabular}




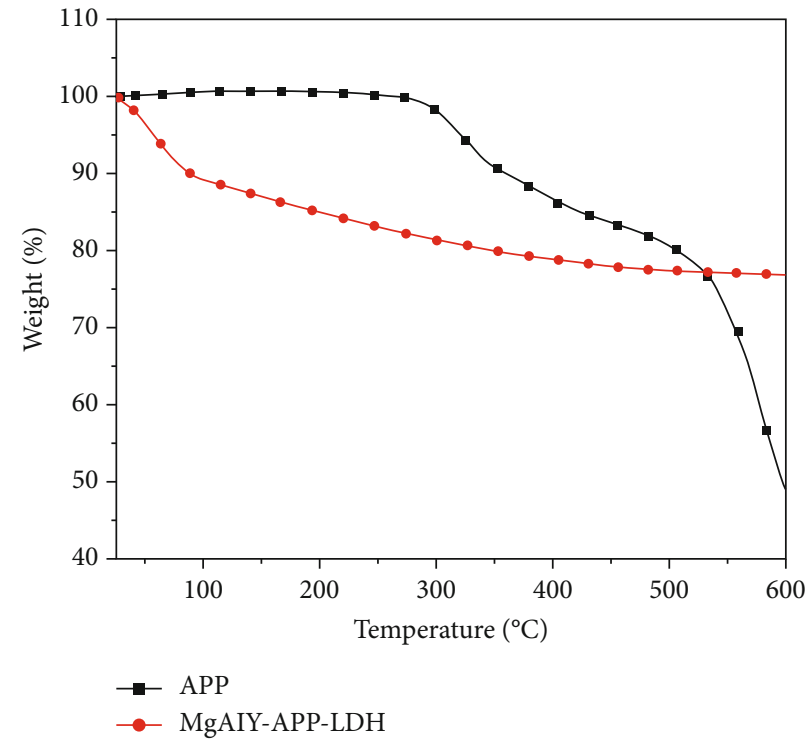

(a)

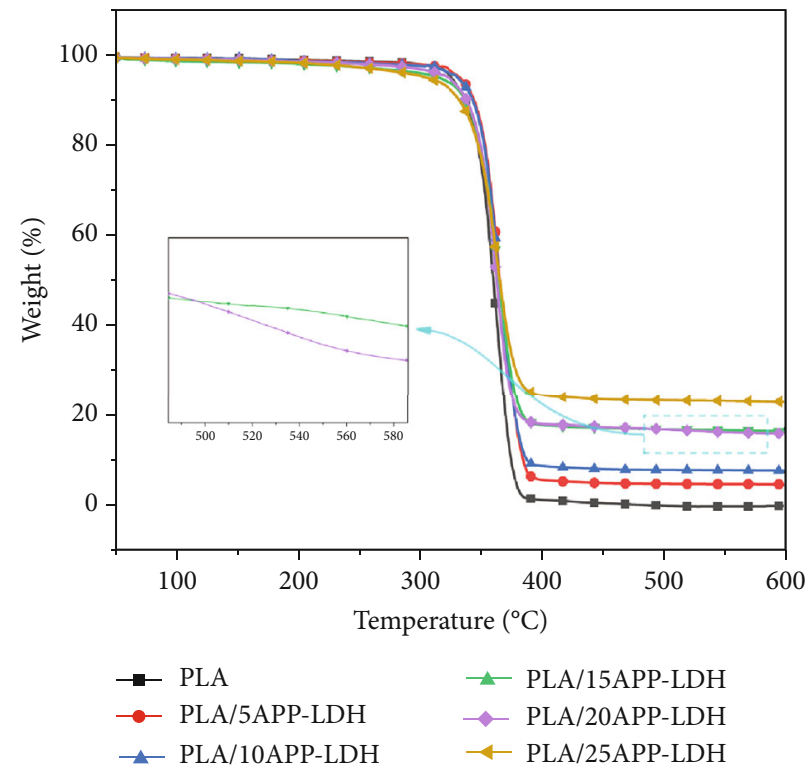

(c)

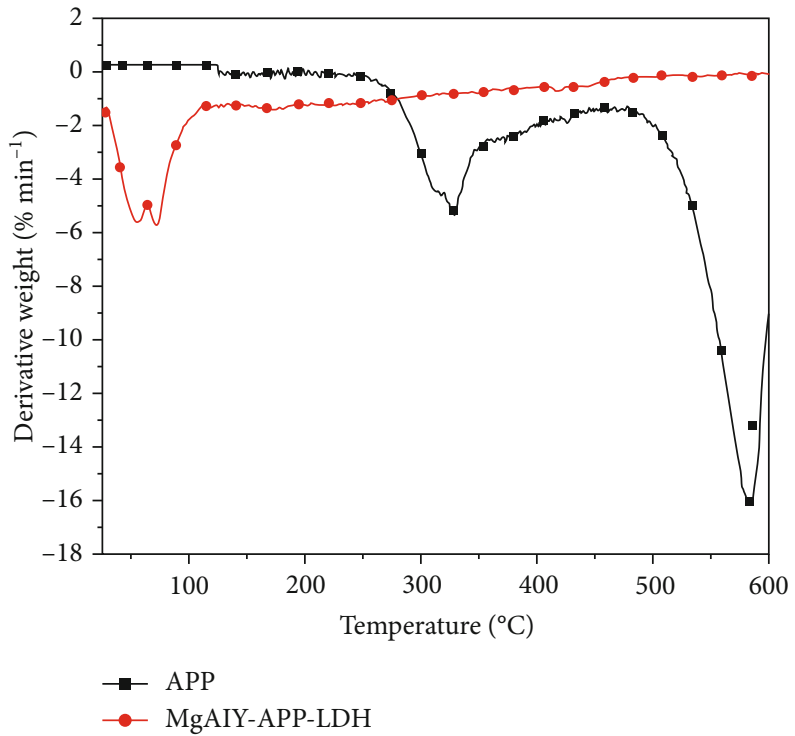

(b)

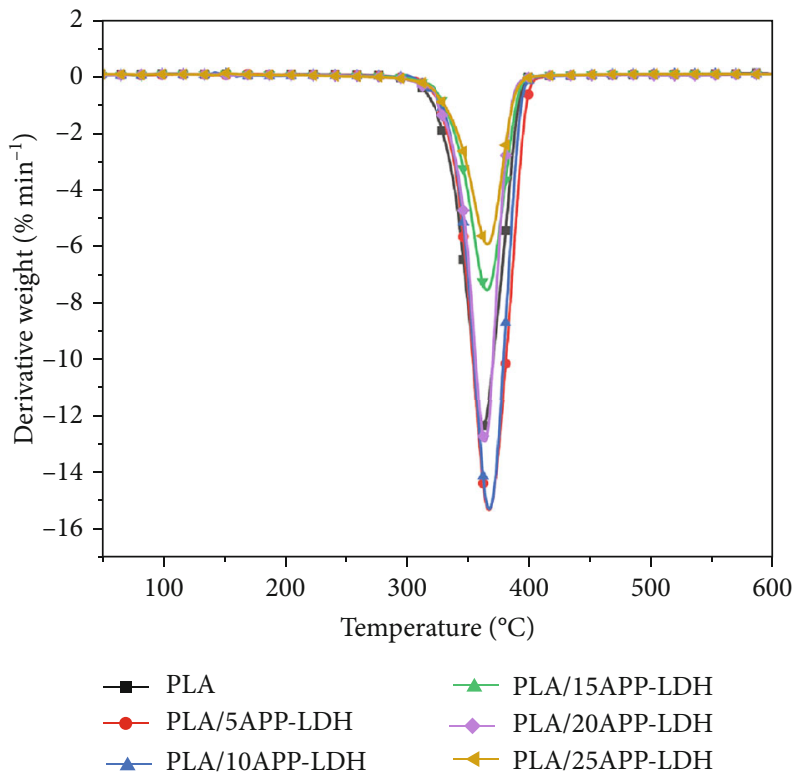

(d)

FIgure 7: (a) TGA and (b) DTG curves of APP and MgAlY-APP-LDHs. (c) TGA and (d) DTG curves of PLA and its composites.

degradation appears at $358^{\circ} \mathrm{C}$. There is no char residue when it is completely degraded at $400^{\circ} \mathrm{C}$ because of its poor carbonization ability [47, 48]. The PLA containing LDHs can be compared with PLA degrades in a similar way; the amount of char residue in the PLA composites is quite noticeable and increases with the addition of LDHs. The introduction of $5,10,15,20$, and $25 \mathrm{wt} \% \mathrm{LDHs}$ increased the char yield of PLA composites from $0.2 \mathrm{wt} \%$ to 4.77 , $7.72,16.48,16.00$, and $22.98 \mathrm{wt} \%$, respectively. The increased char yield implies the reduction of volatile products and fuels during the burning process, which has a positive effect on improving the flame retardancy of PLA $[49,50]$. Combining the results of TGA and DTG together, it can be concluded that LDHs could enhance the thermal stability of PLA.

\subsection{Flame Retardancy of PLA and Its Composites}

3.6.1. UL-94 Vertical Burning Test. Table 2 lists the UL-94 vertical combustion test results of PLA and PLA composites. PLA was extremely flammable and had no rating in the UL-94 test. Although dripping of the melt was observed during the vertical combustion test, PLA/15APP-LDHs composites still reached the UL-94 V-0 rating. The results show that APP-LDHs are an efficient PLA flame retardant, and the obtained PLA composites fully meet the general 


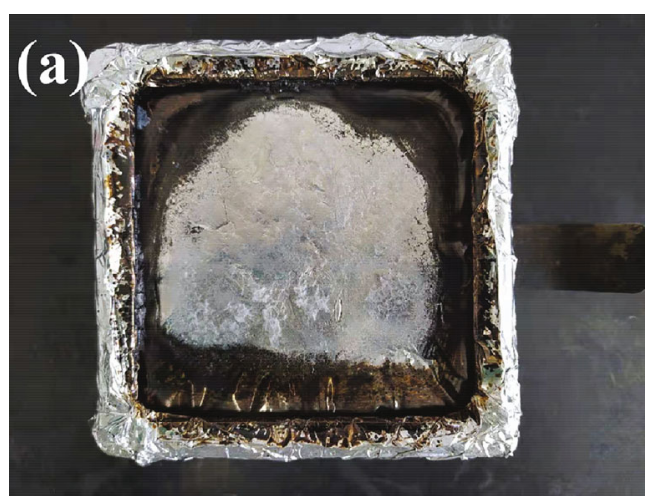

(a)

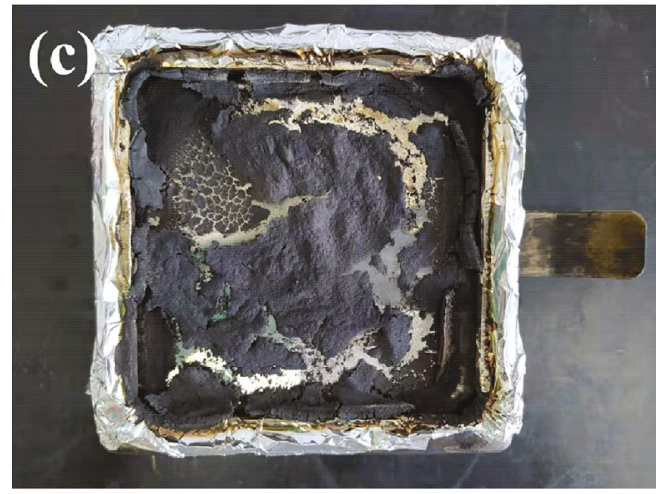

(c)

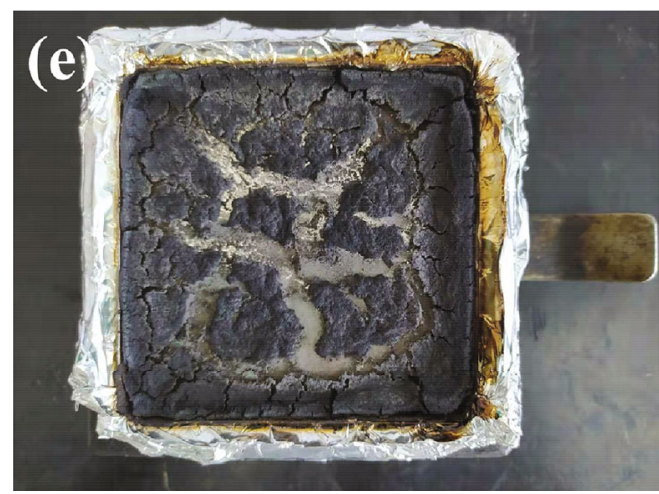

(e)

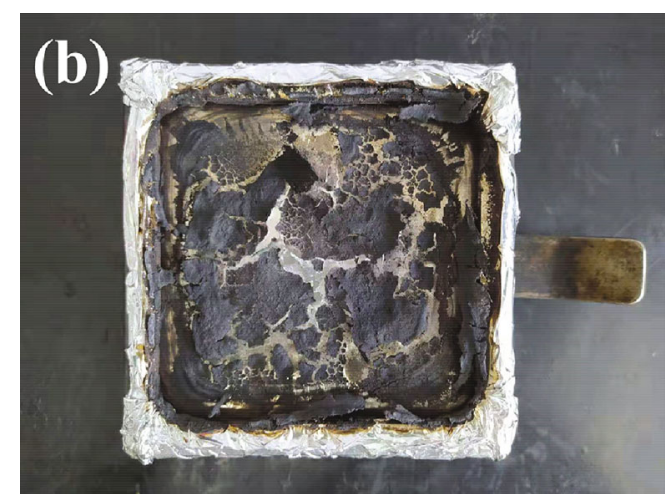

(b)

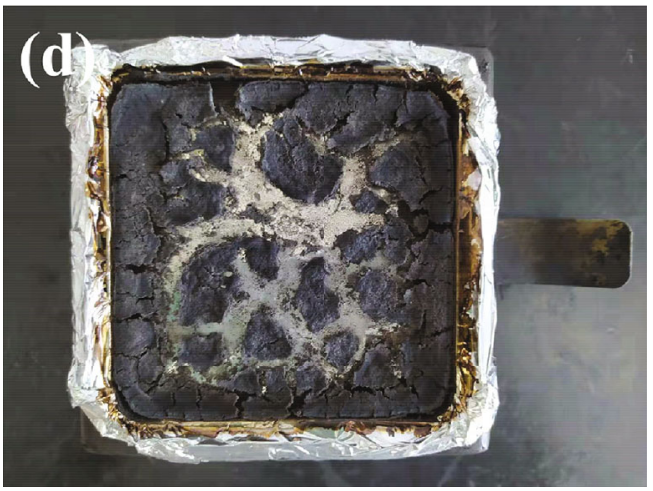

(d)

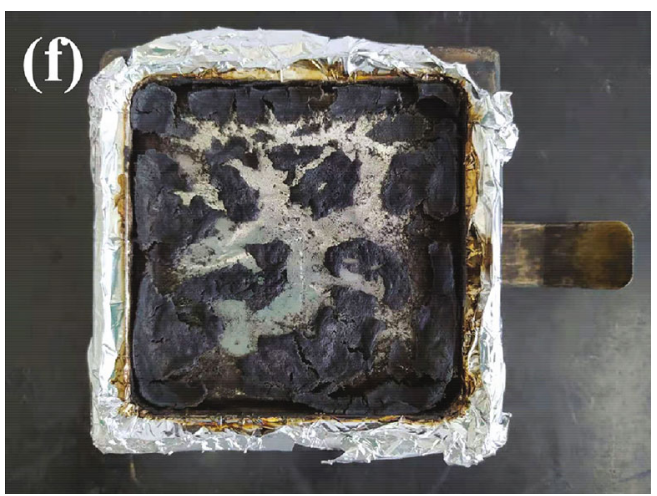

(f)

Figure 8: Photographs of (a) PLA, (b) PLA/5APP-LDHs, (c) PLA/10APP-LDHs, (d) PLA/15APP-LDHs, (e) PLA/20APP-LDHs, and (f) PLA/25APP-LDHs after the cone calorimeter test.

flame-retardant requirements. For the designed APPLDHs, the intercalation effect of APP is beneficial to the interaction between LDHs and PLA matrix, so that LDHs act as a barrier in the condensed phase, which are reflected in the increase in char residue. At the same time, APP generates phosphorus-containing free radicals (PO. and HPO.) in the gas phase, which will interfere with the combustion of PLA and quickly take away the heat of combustion. Therefore, the synergistic effect of these two components in the two stages enables PLA composites to obtain good flame retardancy in the UL-94 tests.
3.6.2. Cone Calorimeter Tests. CCT is used to assess the fire retardancy of composites [36]. Figures 6(a)-6(d) display the HRR, THR, TSP, and residual mass curves of PLA and its composites. Moreover, several major data such as TTI, PHRR, and THR are shown in Table 2. Table 3 lists pure PLA with a high PHHR value of $457 \mathrm{~kW} / \mathrm{m}^{2}$, which reflects its poor fire retardancy. Particularly, PLA/15APP-LDHs show a high PHRR reduction value up to $43 \%$. In addition, compared with pure PLA $\left(76 \mathrm{MJ} / \mathrm{m}^{2}\right)$, PLA loaded with $15 \mathrm{wt} \%$ APP-LDHs can reduce the THR value to $61 \mathrm{MJ} / \mathrm{m}^{2}$. The decrease of THR indicates a great majority of organic structures in the PLA participated in the carbonization 


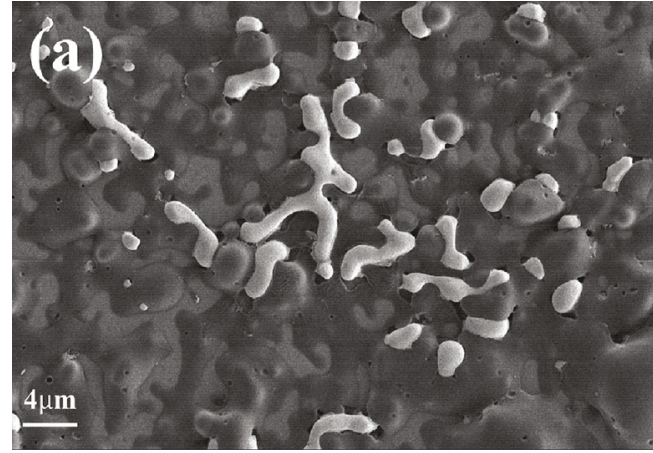

(a)

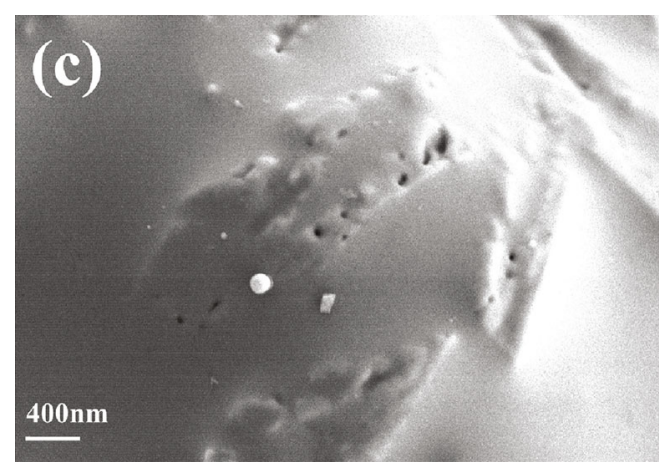

(c)

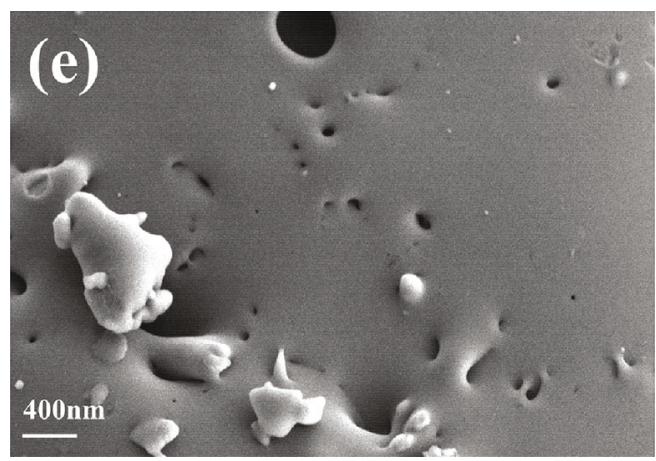

(e)

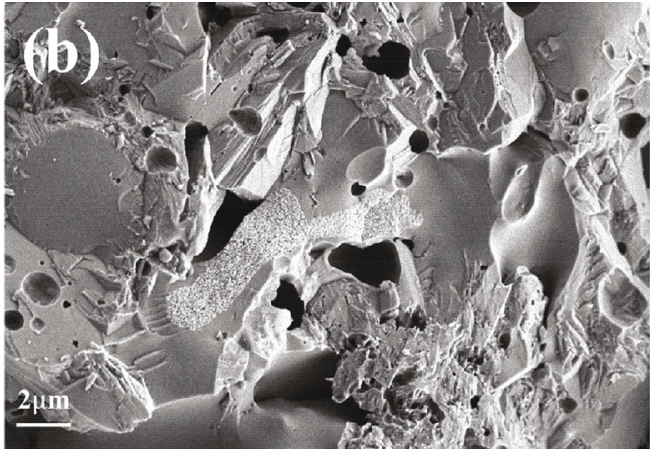

(b)

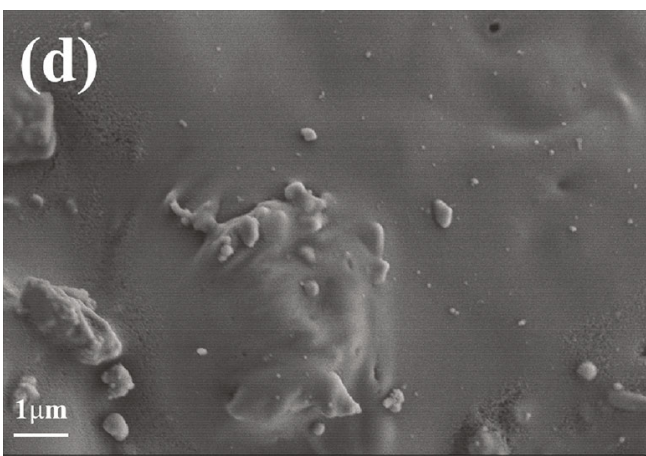

(d)

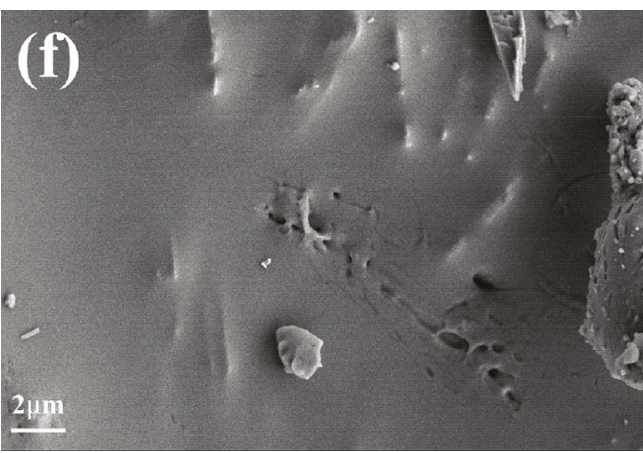

(f)

Figure 9: SEM images of the residual char of (a) PLA, (b) PLA/5APP-LDHs, (c) PLA/10APP-LDHs, (d) PLA/15APP-LDHs, (e) PLA/ 20APP-LDHs, and (f) PLA/25APP-LDHs after the cone calorimeter test.

process and remained in the condensed phase instead of being converted into "fuel" in the gas phase, which is consistent with the TGA results. Moreover, Figure 7(c) clearly shows that the TSP of PLA/15APP-LDHs composite has a significant decrease compared to pure PLA. The possible reason is that the introduction of LDHs reduces the volatilization of organic matter and inhibits the generation of smoke [51]. As for residual mass, it was found that this parameter was increased with the addition of APP-LDHs. The addition of $15 \mathrm{wt} \%$ APP-LDHs can make the char residue of the composite material reach about $18 \%$.

In general, the CCT results indicate that APP-LDHs effectively prevent the degradation of PLA material and improve its flame retardancy. The flame-retardant mechanism can be explained from the condensed phase; APP first thermally decomposes to generate polyphosphoric acid and ammonia and then interacts with - $\mathrm{OH}$ or hydroxyethyl cyanurate to form phosphate ester [52]. After the phosphate ester is dehydrated, a layer of char foam and viscous molten layer will be formed on the polymer surface to suppress thermal oxygen exchange [53, 54]. Meantime, magnesium oxide and aluminum oxide formed after thermal decomposition will accumulate on the surface of PLA to play a role in suppressing the flame.

FRI [55] (flame-retardant index) was a major parameter used to measure the fire retardancy of polymers according to CCT data, which has been calculated by the following formula.

$$
\text { FRI }=\frac{[\text { THR } \times(\text { PHRR } / \text { TTI })]_{\text {Neat PLA }}}{[\text { THR } \times(\text { PHRR } / \text { TTI })]_{\text {PLA composite }}} .
$$


TABLE 4: Calorimetry data of DSC second heating curves of PLA and its composites.

\begin{tabular}{lcccccc}
\hline Sample & $T_{\mathrm{g}}\left({ }^{\circ} \mathrm{C}\right)$ & $T_{\mathrm{cc}}\left({ }^{\circ} \mathrm{C}\right)$ & $\Delta H_{\mathrm{cc}}(\mathrm{J} / \mathrm{g})$ & $T_{\mathrm{m}}\left({ }^{\circ} \mathrm{C}\right)$ & $\Delta H_{\mathrm{m}}(\mathrm{J} / \mathrm{g})$ & $\chi_{c}(\%)$ \\
\hline PLA & 55.50 & 120.20 & 13.05 & 149.70 & 13.23 & 27.70 \\
PLA/5APP-LDHs & 56.00 & 117.40 & 26.57 & 30.00 & 149.50 & 31.35 \\
PLA/10APP-LDHs & 56.10 & 115.70 & 28.74 & 152.1 & 30.65 \\
PLA/15APP-LDHs & 58.30 & 115.10 & 14.74 & 151.7 & 29.74 & 21.53 \\
PLA/20APP-LDHs & 56.50 & 106.70 & 13.91 & 150.0 & 12.85 \\
PLA/25APP-LDHs & 56.70 & 103.60 & & & 18.42 \\
\hline
\end{tabular}

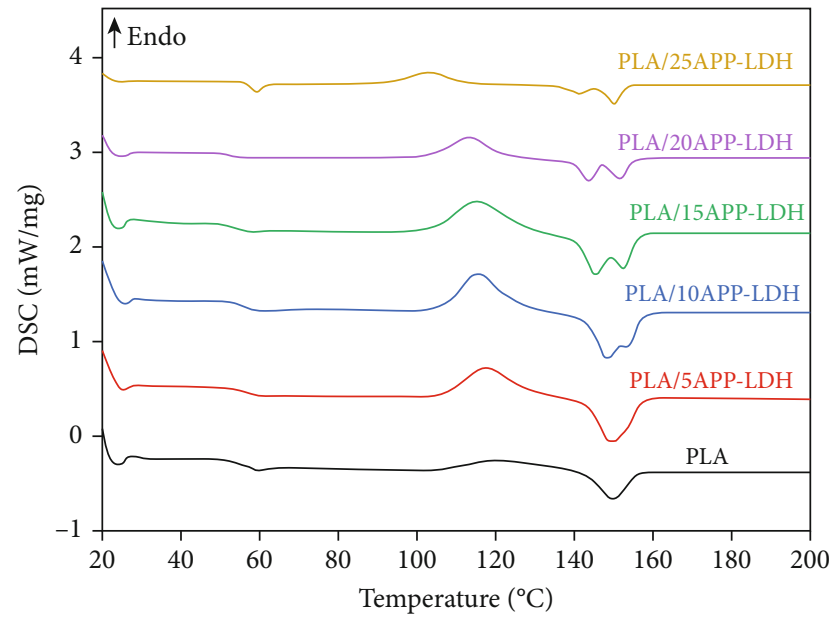

Figure 10: DSC curves of PLA and its composites.

In summary, FRI $<1$ was regarded as the low level of flame retardancy, and $1<\mathrm{FRI}<10$ was regarded as the high-level flame-retardant performance. The FRI value of adding $15 \mathrm{wt} \%$ APP-LDHs was 1.63, indicating the flame retardancy of PLA/15APP-LDH composites has the best performance.

3.6.3. Residue Analysis. The analysis of residual char will provide crucial information about the flame-retardant mechanism. Figure 8 (a) shows that PLA is almost completely burned out with no residual char. A thin char layer was formed on the surface of PLA by the introduction of LDHs, and the residual mass increased significantly with the increase of APP-LDH content.

Besides, it can be clearly seen from the SEM of the char residue that the pores and cracks of the char layer were significantly reduced after adding LDHs, and the surface morphology was more homogeneous and denser. It may be due to the fact that the catalysis of the Y element helps to form a high-performance carbonized layer [56, 57]. The preferred char layer exerts a certain isolation effect during the pyrolysis process of the PLA composites and suppresses the free exchange of flammable volatiles. Significantly, the char layer of PLA/15APP-LDH composite has a denser and more complete microstructure than others (see Figures 9(b)-9(f)), which is more helpful to slowing down combustion and inhibiting the release of heat and smoke [58]. Thus, PLA/15APP-LDHs obtained satisfactory fire resistance.

3.7. DSC of PLA and Its Composites. The DSC test described the crystallization and melting behavior of PLA and PLA composites. Table 4 displays that the $T_{g}$ of pure PLA is $55.50^{\circ} \mathrm{C}$. The PLA composites exhibit a single $T_{g}$ indicating excellent thermodynamic compatibility between LDHs and PLA substrate. The $T_{g}$ of PLA composites has increased due to the introduction of LDHs, which means that the temperature range in which PLA is applied has been expanded. The $T_{c c}$ of PLA is $120.20^{\circ} \mathrm{C}$, and there is a wide cold crystallization zone at $110 \sim 140^{\circ} \mathrm{C}$. The $T_{c c}$ of PLA composites is significantly lower than that of PLA. We further confirmed that LDHs as nucleating agents promote the formation of ordered crystal structure of PLA. It can be observed from Figure 10 that the $T_{\mathrm{m}}$ of PLA composites obviously moved to the higher temperature. The increase in $T_{\mathrm{m}}$ demonstrates that the capability of the PLA molecular segment to move is possibly enhanced thanks to the presence of LDHs. Interestingly, two $T_{\mathrm{m}}$ peaks appeared after the introduction of LDHs; the new peaks moved to higher temperature and became stronger with the amount of LDHs increased. It was illustrated that LDHs played a nucleation role and accelerated the transformation of disordered $\alpha^{\prime}$ crystal to a more perfect $\alpha$ crystal construction in PLA, causing the increase of the $\chi_{c}$ of PLA [59]. Thus, the $\chi_{c}$ of PLA/15APP-LDHs was improved from $14.23 \%$ of PLA to $37.62 \%$. As we all know, the mechanical properties of semicrystalline polymers are affected by crystallinity $[60,61]$. It is essential to inspect the influence of LDHs on the mechanical properties of PLA composites, as discussed below.

3.8. Mechanical Properties of PLA and Its Composites. Figure 11 displays the tensile strength of pure PLA that is 44.26 $\mathrm{MPa}$ and the elongation at break that is only $21.34 \%$. There is no yielding behavior, implying its typical strong and brittle characteristics. In the initial stage, the addition of LDHs causes the decreased tensile strength and elongation at break. The possible reason is that the $\mathrm{LDH}$ nanosheets incline to agglomerate in the PLA matrix, and agglomerates act as stress concentration points leading to brittleness. Although with the continuous increase of LDHs, the mechanical properties of composite materials have rebounded slightly, it is still difficult to maintain the original performance, which is also one of the urgent problems that 


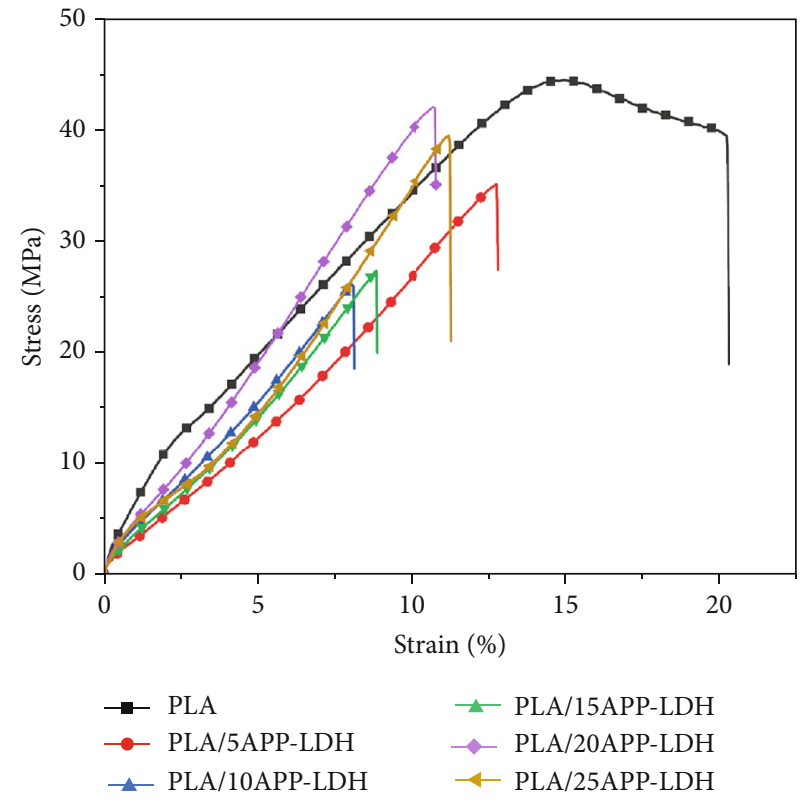

(a)

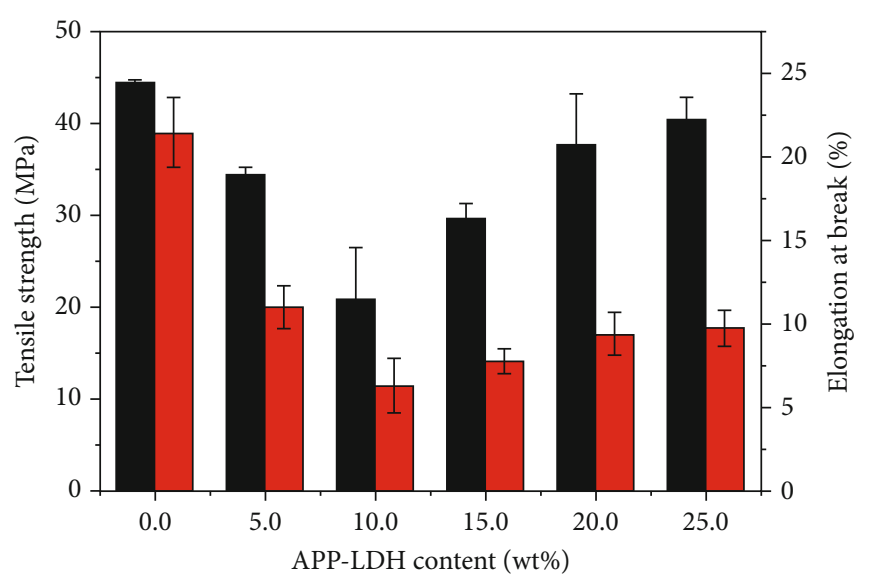

(b)

FIGURE 11: Mechanical properties of PLA and its composites: (a) representative plots of stress vs. strain; (b) tensile strength and elongation at break.

LDH nanoflame-retardant materials need to solve. Hence, the designed APP-LDHs have a slight influence on the mechanical strength of PLA.

\section{Conclusions}

In the research, the nanoflame-retardant MgAlY-APPLDHs were successfully prepared by a simple hydrothermal method and fully characterized. APP-LDHs endowed PLA composites with outstanding fire safety and crystallization performance. PLA/APP-LDH nanocomposites were prepared by melt blending, and their thermal stability, flame retardancy, and mechanical properties were systematically studied. TG results showed that APP-LDHs enhance the $T_{i}$, $T_{\max }$, and char residue of PLA, which confirmed that APPLDHs have a positive effect on the thermal stability of PLA composite. In addition, only $15 \mathrm{wt} \%$ APP-LDHs improved flame retardancy of PLA and made PLA pass the UL-94 V-0 grade. The PHRR and THR of PLA/15APP-LDH composite dropped by $43 \%$ and $20 \%$ compared with pure PLA. This was attributed to the cooperative working mechanisms of APP and LDHs in both condensed and gas phases. Furthermore, the nucleation of APP-LDHs increased the crystallinity of PLA while slightly affecting the tensile strength of PLA. This work supplied a new strategy for the design of heat-resistant and fire-retardant PLA nanocomposites, which held great potential in various realistic applications.

\section{Data Availability}

The data used to support the findings of this study is included within the article.

\section{Conflicts of Interest}

The authors declare that there are no conflicts of interest regarding the publication of this paper.

\section{Acknowledgments}

This research was supported by the Key Special Project of Revitalizing Inner Mongolia (XM2021CXZX02), the Key Technology Research Project of Inner Mongolia Autonomous Region (2020GG0107), the Major Science and Technology Special Project in Inner Mongolia Autonomous Region (2020ZD0026), and the Inner Mongolia Autonomous Region Talent Introduction Project (2020CG0069).

\section{References}

[1] P. Majgaonkar, R. Hanich, F. Malz, and R. Brüll, "Chemical recycling of post-consumer PLA waste for sustainable production of ethyl lactate," Chemical Engineering Journal, vol. 423, 2021.

[2] C. Moretti, L. Hamelin, L. G. Jakobsen et al., "Cradle-to-grave life cycle assessment of single-use cups made from PLA, PP and PET," Resources, Conservation and Recycling, vol. 169, 2021.

[3] S. Bhagia, K. Bornani, R. Agrawal et al., "Critical review of FDM 3D printing of PLA biocomposites filled with biomass resources, characterization, biodegradability, upcycling and opportunities for biorefineries," Applied Materials Today, vol. 24, 2021.

[4] K. Meinander, M. Niemi, J. S. Hakola, and J. F. Selin, "Polylactides - degradable polymers for fibres and films," Macromolecular Symposia, vol. 123, no. 1, pp. 147-153, 1997. 
[5] D. Da Costa, C. Exbrayat-Héritier, B. Rambaud et al., "Surface charge modulation of rifampicin-loaded PLA nanoparticles to improve antibiotic delivery in Staphylococcus aureus biofilms," Journal of Nanobiotechnology, vol. 19, no. 1, p. 12, 2021.

[6] H. Wu, Q. He, L. Li et al., "A facile and versatile superhydrophilic coating on biodegradable PLA stent with stepwise assembly of metal/phenolic networks for mimicking endothelium function," Chemical Engineering Journal, vol. 427, 2022.

[7] F. Uddin, "Flame-retardant fibrous materials in an aircraft," Journal of Industrial Textiles, vol. 45, no. 5, pp. 1128-1169, 2016.

[8] X. Zhao, L. Chen, D.-F. Li et al., "Biomimetic construction peanut-leaf structure on ammonium polyphosphate surface: improving its compatibility with poly(lactic acid) and flameretardant efficiency simultaneously," Chemical Engineering Journal, vol. 412, 2021.

[9] Y. Zhang, J. Jing, T. Liu et al., "A molecularly engineered bioderived polyphosphate for enhanced flame retardant, UVblocking and mechanical properties of poly(lactic acid)," Chemical Engineering Journal, vol. 411, 2021.

[10] Y. Li, S. Qiu, J. Sun et al., “A new strategy to prepare fully biobased poly(lactic acid) composite with high flame retardancy, UV resistance, and rapid degradation in soil," Chemical Engineering Journal, vol. 428, 2022.

[11] H. Vahabi, F. Laoutid, M. Mehrpouya, M. R. Saeb, and P. Dubois, "Flame retardant polymer materials: an update and the future for 3D printing developments," Materials Science and Engineering: R: Reports, vol. 144, 2021.

[12] T. Tirri, M. Aubert, H. Aziz, Y. Brusentsev, W. Pawelec, and C. E. Wilén, "Sulfenamides in synergistic combination with halogen free flame retardants in polypropylene," Polymer Degradation and Stability, vol. 164, pp. 75-89, 2019.

[13] Y. Chen, L. Li, and L. Qian, "The pyrolysis behaviors of phosphorus-containing organosilicon compound modified ammonium polyphosphate with different phosphoruscontaining groups, and their different flame-retardant mechanisms in polyurethane foam," RSC Advances, vol. 8, no. 48, pp. 27470-27480, 2018.

[14] J. Lv, L. Z. Qiu, and B. J. Qu, "Controlled synthesis of magnesium hydroxide nanoparticles with different morphological structures and related properties in flame retardant ethylenevinyl acetate blends," Nanotechnology, vol. 15, no. 11, pp. 1576-1581, 2004.

[15] Z. Yin, J. Lu, N. Hong et al., "Functionalizing $\mathrm{Ti}_{3} \mathrm{C}_{2} \mathrm{~T}_{\mathrm{x}}$ for enhancing fire resistance and reducing toxic gases of flexible polyurethane foam composites with reinforced mechanical properties," Journal of Colloid and Interface Science, vol. 607, Part 2, pp. 1300-1312, 2022.

[16] J. Lu, Y. Zhang, Y. Tao et al., "Self-healable castor oil-based waterborne polyurethane/MXene film with outstanding electromagnetic interference shielding effectiveness and excellent shape memory performance," Journal of Colloid and Interface Science, vol. 588, pp. 164-174, 2021.

[17] Y. Zhang, W. Tian, L. Liu et al., "Eco-friendly flame retardant and electromagnetic interference shielding cotton fabrics with multi-layered coatings," Chemical Engineering Journal, vol. 372, pp. 1077-1090, 2019.

[18] W. Zhan, L. Ni, Z. Gu, F. Cui, J. Jiang, and L. Chen, "The influences of graphene and carbon nanotubes on properties of waterborne intumescent fire resistive coating," Powder Technology, vol. 385, pp. 572-579, 2021.
[19] A. Esmailpour, R. Majidi, H. R. Taghiyari, M. Ganjkhani, S. M. Mohseni Armaki, and A. N. Papadopoulos, "Improving fire retardancy of beech wood by graphene," Polymers, vol. 12, no. $2,2020$.

[20] P. Jia, C. Ma, J. Lu et al., "Design of copper [email protected] nanohybrids to accomplish excellent resilience and superior fire safety for flexible polyurethane foam," Journal of Colloid and Interface Science, vol. 606, Part 2, pp. 1205-1218, 2022.

[21] C. Motzkus, C. Chivas-Joly, E. Guillaume et al., "Aerosols emitted by the combustion of polymers containing nanoparticles," Journal of Nanoparticle Research, vol. 14, no. 3, 2012.

[22] V. Pachta, E.-C. Tsardaka, and M. Stefanidou, "The role of flame retardants in cement mortars exposed at elevated temperatures," Construction and Building Materials, vol. 273, 2021.

[23] R. Zhou, Z. Ming, J. He, Y. Ding, and J. Jiang, "Effect of magnesium hydroxide and aluminum hydroxide on the thermal stability, latent heat and flammability properties of paraffin/ HDPE phase change blends," Polymers, vol. 12, no. 1, 2020.

[24] Z. Yin, B. Wang, Q. Tang et al., "Inspired by placoid scale to fabricate MXene derivative biomimetic structure on the improvement of interfacial compatibility, mechanical property, and fire safety of epoxy nanocomposites," Chemical Engineering Journal, vol. 431, 2022.

[25] W. Cheng, Y. Zhang, Y. Tao et al., "Durable electromagnetic interference (EMI) shielding ramie fabric with excellent flame retardancy and self-healing performance," Journal of Colloid and Interface Science, vol. 602, pp. 810-821, 2021.

[26] Y. Gao, T. W. Teoh, Q. Wang, and G. R. Williams, "Electrospun organic-inorganic nanohybrids as sustained release drug delivery systems," Journal of Materials Chemistry, vol. 5, no. 46, pp. 9165-9174, 2017.

[27] Q. Qin, J. Wang, T. Zhou et al., "Impact of organic interlayer anions on the $\mathrm{CO}_{2}$ adsorption performance of $\mathrm{Mg}$-Al layered double hydroxides derived mixed oxides," Journal of Energy Chemistry, vol. 26, no. 3, pp. 346-353, 2017.

[28] J. Wang, Y. Yang, L. Jia et al., "The influence of the charge compensating anions of layered double hydroxides (LDHs) in LDH-NS/graphene oxide nanohybrid for $\mathrm{CO}_{2}$ capture," Journal of Nanoscience and Nanotechnology, vol. 18, 2018.

[29] M. Wang, J. Lian, X. Zhou, and Y. Lian, "Supercapacitors based on the composite of graphene and NiFe-layered double hydroxides," Science of Advanced Materials, vol. 9, no. 2, pp. 220-226, 2017.

[30] L. Zhou, M. Shao, M. Wei, and X. Duan, "Advances in efficient electrocatalysts based on layered double hydroxides and their derivatives," Journal of Energy Chemistry, vol. 26, no. 6, pp. 1094-1106, 2017.

[31] M. Wei, Q. Huang, Y. Zhou, Z. Peng, and W. Chu, "Ultrathin nanosheets of cobalt-nickel hydroxides hetero-structure via electrodeposition and precursor adjustment with excellent performance for supercapacitor," Journal of Energy Chemistry, vol. 27, no. 2, pp. 591-599, 2018.

[32] Y. Liu, Y. Gao, Q. Wang, and W. Lin, “The synergistic effect of layered double hydroxides with other flame retardant additives for polymer nanocomposites: a critical review," Dalton Transactions, vol. 47, no. 42, pp. 14827-14840, 2018.

[33] X. $\mathrm{Hu}$ and Z. Sun, "Nano $\mathrm{CaAlCO}_{3}$-layered double hydroxide-doped intumescent fire-retardant coating for mitigating wood fire hazards," Journal of Building Engineering, vol. 44, 2021. 
[34] H. Zhang, X. Hu, Y. Liu, S. Zhang, and Z. Wu, "Convenient synthesis of one-dimensional [email protected] via selfassembly towards simultaneously improved fire retardance, mechanical strength and thermal resistance for epoxy resin," Composites Part B: Engineering, vol. 216, 2021.

[35] L. Li, Y. Qian, P. Qiao, H. Han, and H. Zhang, "Preparation of LDHs based on bittern and its flame retardant properties in EVA/LDHs composites," Advances in Polymer Technology, vol. 2019, Article ID 4682164, 13 pages, 2019.

[36] Z. Keqing, G. Rui, and Q. Xiaodong, "Self-assembly of exfoliated molybdenum disulfide $\left(\mathrm{MoS}_{2}\right)$ nanosheets and layered double hydroxide (LDH): towards reducing fire hazards of epoxy," Journal of Hazardous Materials, vol. 338, pp. 343355, 2017.

[37] S. Xu, M. Zhang, S. Y. Li et al., "Intercalation of a novel containing nitrogen and sulfur anion into hydrotalcite and its highly efficient flame retardant performance for polypropylene," Applied Clay Science, vol. 191, 2020.

[38] S. Xu, L. Zhang, Y. Lin, R. Li, and F. Zhang, "Layered double hydroxides used as flame retardant for engineering plastic acrylonitrile-butadiene-styrene (ABS)," Journal of Physics and Chemistry of Solids, vol. 73, no. 12, pp. 1514-1517, 2012.

[39] X. Shan, L. Song, W. Xing, Y. Hu, and S. Lo, "Effect of nickelcontaining layered double hydroxides and cyclophosphazene compound on the thermal stability and flame retardancy of poly(lactic acid)," Industrial \& Engineering Chemistry Research, vol. 51, no. 40, pp. 13037-13045, 2012.

[40] S. Zhou, Y. Yang, Z. Zhu et al., "Preparation of a halogen-free flame retardant and its effect on the poly(L-lactic acid) as the flame retardant material," Polymer, vol. 229, 2021.

[41] B. Wang, J. Li, X. Lai, H. Li, Y. Chen, and X. Zeng, "Synthesis of a novel $\mathrm{N}$-alkoxyamine containing macromolecular intumescent flame retardant and its synergism in flame-retarding polypropylene," Polymers for Advanced Technologies, vol. 32, no. 6, pp. 2452-2464, 2021.

[42] J. Qin, P. Xie, Y. Tian, H. Zhang, and J. Yu, "Preparation and characterisation of ammonium polyphosphate intercalated layered double hydroxides composite by joint method with or without sonochemical technique," Journal of Thermal Analysis and Calorimetry, vol. 110, no. 3, pp. 1193-1198, 2012.

[43] Y. Liu, Y. Gao, Z. Zhang, and Q. Wang, "Preparation of ammonium polyphosphate and dye co-intercalated LDH/ polypropylene composites with enhanced flame retardant and UV resistance properties," Chemosphere, vol. 277, 2021.

[44] L. Liu, Y. Xu, Y. Pan, M. Xu, Y. di, and B. Li, "Facile synthesis of an efficient phosphonamide flame retardant for simultaneous enhancement of fire safety and crystallization rate of poly (lactic acid)," Chemical Engineering Journal, vol. 421, 2021.

[45] Z. Li, Z. Xue, B. Yang, B. Wang, and X. Peng, "One-pot in situ synthesis of hollow layered double hydroxide-ammonium polyphosphate nanoshells toward flame retardant," Chemistry Letters, vol. 43, no. 12, pp. 1879-1881, 2014.

[46] Y. Gao, Q. Wang, L. Qiu et al., "Ethylene-VInyl acetate/LDH nanocomposites with enhanced thermal stability, flame retardancy, and rheological property," Polymer Composites, vol. 37, no. 12, pp. 3449-3459, 2016.

[47] Y. Xue, J. Feng, S. Huo et al., "Polyphosphoramide-intercalated MXene for simultaneously enhancing thermal stability, flame retardancy and mechanical properties of polylactide," Chemical Engineering Journal, vol. 397, 2020.
[48] J.-Y. Si, B. Tawiah, W.-L. Sun et al., "Functionalization of MXene nanosheets for polystyrene towards high thermal stability and flame retardant properties," Polymers, vol. 11, no. 6, 2019.

[49] F. Fang, S. Huo, H. Shen et al., "A bio-based ionic complex with different oxidation states of phosphorus for reducing flammability and smoke release of epoxy resins," Composites Communications, vol. 17, pp. 104-108, 2020.

[50] G. Huang, S. Huo, X. Xu et al., "Realizing simultaneous improvements in mechanical strength, flame retardancy and smoke suppression of ABS nanocomposites from multifunctional graphene," Composites Part B: Engineering, vol. 177, 2019.

[51] E. N. Kalali, X. Wang, and D.-Y. Wang, "Functionalized layered double hydroxide-based epoxy nanocomposites with improved flame retardancy and mechanical properties," Journal of Materials Chemistry A, vol. 3, no. 13, pp. 6819-6826, 2015.

[52] M. Lewin, "Synergistic and catalytic effects in flame retardancy of polymeric materials-an overview," Journal of Fire Sciences, vol. 17, no. 1, pp. 3-19, 1999.

[53] K.-S. Lim, S.-T. Bee, L. T. Sin et al., "A review of application of ammonium polyphosphate as intumescent flame retardant in thermoplastic composites," Composites Part B: Engineering, vol. 84, pp. 155-174, 2016.

[54] X. Zhou and T. Wu, "Synthesis, characterization of phosphorus-containing copolyester and its application as flame retardants for poly(butylene succinate) (PBS)," Chemosphere, vol. 235, pp. 163-168, 2019.

[55] H. Vahabi, B. K. Kandola, and M. R. Saeb, "Flame retardancy index for thermoplastic composites," Polymers, vol. 11, no. 3, 2019.

[56] P. Jia, X. Yu, J. Lu et al., "The $\mathrm{Re}_{2} \mathrm{Sn}_{2} \mathrm{O}_{7}(\mathrm{Re}=\mathrm{Nd}, \mathrm{Sm}, \mathrm{Gd})$ on the enhancement of fire safety and physical performance of polyolefin/IFR cable materials," Journal of Colloid and Interface Science, vol. 608, Part 2, pp. 1652-1661, 2022.

[57] W. Y. Liu, H. Wen, Y. Xiao, Y. H. Li, L. Yin, and G. Y. Bai, "Inhibiting effects of layered double hydroxides containing the rare-earth element lanthanum on coal spontaneous combustion," Thermochimica Acta, vol. 687, 2020.

[58] N. Wu, G. Fu, Y. Yang, M. Xia, H. Yun, and Q. Wang, "Fire safety enhancement of a highly efficient flame retardant poly(phenylphosphoryl phenylenediamine) in biodegradable poly(lactic acid)," Journal of Hazardous Materials, vol. 363, pp. 1-9, 2019.

[59] H. Qiao, J. Guo, L. Wang et al., "Effects of divinylbenzenemaleic anhydride copolymer hollow microspheres on crystallization behaviors, mechanical properties and heat resistance of poly(l-lactide acid)," Polymers for Advanced Technologies, vol. 31, no. 4, pp. 817-826, 2020.

[60] Y.-G. Zhou, W.-B. Wu, G.-Y. Lu, and J. Zou, "Isothermal and non-isothermal crystallization kinetics and predictive modeling in the solidification of poly(cyclohexylene dimethylene cyclohexanedicarboxylate) melt," Journal of Elastomers \& Plastics, vol. 49, no. 2, pp. 132-156, 2017.

[61] B. Su and Y.-G. Zhou, "Improvement of transparencies and mechanical properties of poly(cyclohexylene dimethylene cyclohexanedicarboxylate) parts using a compounding nucleating agent to control crystallization," Materials, vol. 12, no. 4 , p. $563,2019$. 